\title{
Nutritional Status and Quality of Life in Patients Admitted for Gastrointestinal Surgery
}

\author{
M. Abirami*, R. Sangami and A. J. Hemamalini \\ ${ }^{1} P G$, Department of Clinical Nutrition, Sri Ramachandra University, Chennai - 600116, Tamil Nadu, \\ India; abindindia@gmail.com \\ ${ }^{2}$ Assistant Professor, Department of Clinical Nutrition, Sri Ramachandra University, \\ Chennai - 600116, Tamil Nadu, India \\ ${ }^{3}$ Associate Professor and HOD, Department of Clinical Nutrition, Sri Ramachandra \\ University, Chennai - 600116, Tamil Nadu, India
}

\begin{abstract}
The physiological and psychosocial stresses of surgery increase the risk of poor nutritional status, which is clearly linked to poorer outcomes. Poor nutrition therefore has its consequences on quality of life. The evaluation of Quality of Life assesses patients' well-being by taking into account physical, psychological and social conditions. The objectives are to assess the anthropometric parameters, Biochemical parameters, diet history and Quality of Life of the study subjects using Gastrointestinal Quality of Life Index questionnaire (GOQLI) and to compare the nutritional status and Quality of Life scores and to correlate the anthropometric, biochemical parameters and nutrient intake with GIQLI scores. A prospective study using convenient sampling technique was conducted on 50 study subjects to assess their nutritional status and gastrointestinal quality of life. In this study the GIQLI score was divided into overall, physical, emotional and gastrointestinal domains. Observations showed nutritional status had significant association $(\mathrm{p}<0.05)$ with physical domain $(12.12 \pm 14.15)$. In biochemical parameter albumin had significant association $(p<0.05)$ with emotional domain and nutrient intake was found to have significant association $(\mathrm{p}<0.01)$ with emotional domain. In patients admitted for GI surgery the overall and domain specific scores were found to be less when compared with the scores of normal subjects as reported in the previous studies. The overall and domain specific GIQLI scores seem to have association with varying weight loss, serum albumin and nutrient intake. It is understood that gastrointestinal Quality of Life has major impact on the underlying disease progression and recovery, appropriate nutritional intervention and support should be provided at the earliest to prevent further decline in nutritional status and post-operative complications.
\end{abstract}

Keywords: Gastrointestinal Quality of Life Index Questionnaire (GOQLI), Gastrointestinal Surgery

\section{Introduction}

Protein-energy malnutrition is a common problem in hospital patients. Studies have reported $40 \%$ of surgical and medical patients to be malnourished on admission to hospital. The majority of patients experienced nutritional depletion during the course of their hospital admission, which was more severe in those patients who were already depleted at the time of their admission ${ }^{1}$. Changes in body composition, tissue wasting, and impaired organ functions lead to impaired immune and muscle function ${ }^{2}$. Stress of surgery, reduced intake and subsequent increase in metabolic rate leads to poor surgical outcome $e^{3}$. Nutritional status has been shown to affect quality of life, tolerance of future treatments and survival in people having undergone major upper gastrointestinal surgery ${ }^{4}$. WHO has defined Quality of Life (QOL) as "an individual's perception of their position in life in the 
context of the culture and value systems in which they live and in relation to their goals, expectations, standards and concerns ${ }^{5}$.

\section{Materials and Methods}

The present observational study was carried out at Sri Ramachandra Hospital, Porur, Chennai. The proposal of the study was submitted to the Institutional Ethical Committee of Sri Ramachandra University, Porur and was approved by the committee. Participation in this study was completely voluntary, written informed consent was obtained from each participant before participating in this study. The study duration was four months. The sampling technique adopted in the study was "Convenient sampling technique". Sample selection was done according to the inclusion and exclusion criteria. Inclusion criteria: Both genders, age: $>18-75$ years subjects admitted for any GI surgery, Subjects with other co-morbidities. Exclusion criteria: Pediatric age group, pregnant and lactating mothers. The study involves a sample size of 50 subjects. The subjects were assessed on demographic data (Name, age, sex, diagnosis, past medical history and social habits), nutritional status (anthropometric parameters - Height, Weight, BMI), Biochemical parameters (Hemoglobin, Total count, Total protein, Albumin, Globulin) Diet History (Diet pattern, Food frequency questionnaire, 3 days food recall) and Gastrointestinal Quality of Life using GIQLI Questionnaire. The GIQLI explores the patient's selfevaluation. It includes 36 items covering four domains. Three domains belong to the general quality of life: Physical function (8 questions), emotional function (9 questions). One domain is specific to gastrointestinal symptoms (19 questions). Each question is scored from zero to four (most desirable option: 4 points and least desirable option: 0 points). The study subjects were counseled based on their nutritional status, food intake and Quality of Life scores.

Descriptive statistics such as percentage, mean and standard deviation were used to describe the various characteristics such as demographic data, anthropometry parameters (Height, weight, BMI), Biochemical parameters (Hemoglobin, Total count, Total Protein, albumin, globulin) and the nutrient intake using diet history (3 day nutrient intake, diet pattern) among the study subjects. The inferential analysis was done with SPSS 16.0 version. To describe about the data descriptive statistics frequency analysis, percentage analysis was used for categorical variables and for continuous variables the mean and S.D were used. To find the significance difference between the bivariate samples in Independent groups Mann-whitney U test was used for skewed data and for the normal data unpaired $t$-test was used. For the multivariate analysis the Kruskal Walli's test was used. To assess the relationship between the variables Pearson's Correlation was used. To find the significance in categorical data Chi-square test was used. In all the above statistical tools the probability value 0.05 is considered as significant level.

\section{Results and Discussion}

\subsection{Distribution of Subjects based on Diagnosis}

Among the 50 study subjects' male subjects had higher percentage of gastro intestinal complications (54\%) than the female subjects (46\%) and subjects in older adults and geriatric age group seems to have higher prevalence of GI complications.

In male subject's cancer stomach was about $18.5 \%$, followed by cancer esophagus and Gastric Outlet Obstruction of about 7.40\%, Gastro esophageal Reflux Disease (GERD) of $5.5 \%$, cancer colon of $2.7 \%$, remaining Bile Reflux Gastritis, TB abdomen, achalasia cardia and Gastro Intestinal Stromal Tumors of $1.85 \%$. In female subjects cancer colon and Intestinal obstruction of about $8.69 \%$, followed by Gastro esophageal Reflux Disease of 6.5\%, Gastric Outlet Obstruction (GOO), Bile Reflux Gastritis and adhesive colic of $4.34 \%$, remaining esophageal stricture, esophageal web, cancer stomach, cancer esophagus, TB abdomen, ileocecal TB of $2.17 \%$ respectively (Table 1).

\subsection{Co-morbid conditions}

Among the study subjects $3.70 \%$ of male subjects and $8.69 \%$ of female subjects were found to be diabetic. Only female subjects of about $2.17 \%$ had previous history of hypertension. About $8.69 \%$ of female subjects were found to have both diabetes and hypertension. HTN and CAD were found to be in about $1.85 \%$ of male subjects and in $2.17 \%$ of female subjects and about $44.44 \%$ of male subjects and $28.26 \%$ of female subjects were found to have no co-morbidities (Table 2). 
Table 1. Percentage distribution of subjects based on diagnosis

\begin{tabular}{|c|c|c|c|c|}
\hline \multirow{2}{*}{ Diagnosis } & \multicolumn{2}{|c|}{ Male $(\mathrm{N}=$} & \multicolumn{2}{c|}{$\begin{array}{c}\text { Female } \\
(\mathrm{N}=23)\end{array}$} \\
\cline { 2 - 5 } & $\mathrm{N}$ & $\%$ & $\mathrm{~N}$ & $\%$ \\
\hline Gerd & 3 & 5.5 & 3 & 6.5 \\
\hline Ca Colon & 2 & 2.7 & 4 & 8.69 \\
\hline Goo & 4 & 7.40 & 2 & 4.34 \\
\hline Oesophagial Web & 0 & - & 1 & 2.17 \\
\hline Intestinal Obstruction & 0 & - & 4 & 8.69 \\
\hline Ca Oesophagus & 4 & 7.40 & 1 & 2.17 \\
\hline Ca Stomach & 10 & 18.51 & 1 & 2.17 \\
\hline Bile Reflux Gastritis & 1 & 1.85 & 2 & 4.34 \\
\hline Tb Abdomen & 1 & 1.85 & 1 & 2.17 \\
\hline Achalasia Cardia & 1 & 1.85 & 0 & - \\
\hline Ileocaecal Tuberculosis & 0 & - & 1 & 2.17 \\
\hline Oesophagial Stricture & 0 & - & 1 & 2.17 \\
\hline Adhesive Colic & 0 & - & 2 & 4.34 \\
\hline Gist & 1 & 1.85 & 0 & - \\
\hline
\end{tabular}

Table 2. Percentage distribution of subjects based on co-morbid conditions

\begin{tabular}{|c|c|c|c|c|}
\hline \multirow{2}{*}{$\begin{array}{c}\text { Co-morbid } \\
\text { Conditions }\end{array}$} & \multicolumn{2}{|c|}{ Male $(\mathrm{N}=\mathbf{2 7})$} & \multicolumn{2}{c|}{ Female $(\mathrm{N}=\mathbf{2 3})$} \\
\cline { 2 - 5 } & $\mathrm{N}$ & $\mathbf{\%}$ & $\mathrm{N}$ & $\%$ \\
\hline DM & 2 & 3.70 & 4 & 8.69 \\
\hline HTN & - & - & 1 & 2.17 \\
\hline DM AND HTN & - & - & 4 & 8.69 \\
\hline HTN AND CAD & 1 & 1.85 & 1 & 2.17 \\
\hline NONE & 24 & 44.44 & 13 & 28.26 \\
\hline
\end{tabular}

Study revealed that most of the subjects had anorexia and early satiety (Table 3 ).

\subsection{Hunger and Satiety of Subjects}

Table 3. Percentage distribution of subjects based on subjective data

\begin{tabular}{|l|c|c|c|c|c|}
\hline \multirow{3}{*}{$\begin{array}{l}\text { Subjective } \\
\text { Data }\end{array}$} & \multirow{2}{*}{$\begin{array}{c}\text { Male } \\
(\mathbf{N}=\mathbf{2 7})\end{array}$} & \multicolumn{2}{c|}{$\begin{array}{c}\text { Female } \\
(\mathbf{N}=23)\end{array}$} \\
\hline \multirow{4}{*}{ Appetite } & Normal & 14 & 25.9 & 11 & 23.9 \\
\cline { 2 - 6 } & Anorexic & 9 & 16.6 & 10 & 21.7 \\
\cline { 2 - 6 } & Polyphagia & 4 & 7.40 & 2 & 4.34 \\
\hline \multirow{4}{*}{ Hunger } & Satiated & 14 & 25.91 & 11 & 23.9 \\
\cline { 2 - 6 } & $\begin{array}{c}\text { Early } \\
\text { Satiated }\end{array}$ & 9 & 16.6 & 10 & 21.7 \\
\cline { 2 - 6 } & $\begin{array}{c}\text { Delayed } \\
\text { Satiated }\end{array}$ & 4 & 7.40 & 2 & 4.34 \\
\hline
\end{tabular}

Vol 6 (1) | January-June 2019 |

\subsection{Nutritional Assessment}

The height measurement (Figure 1) was found to be normal both in male and female subjects (168.02 \pm 8.38 , $152.13 \pm 6.53)$ when compared with standard values, whereas weight measurement was found to be less than the standard values both in male and female subjects $(52.9 \pm 9.9,50.7 \pm 13.06)$. Body Mass Index reveals that about $35.1 \%$ of male and $30.4 \%$ of female subjects were well nourished, $11.1 \%$ of male and $6.52 \%$ of female subjects were under nourished. Overweight and obesity was seen in about $1.85 \%$ in male and $6.52 \%$ in female subjects respectively (Table 4 ).

Weight loss was reported by the subjects for minimum of $11 / 2$ months to maximum of 3 months. Among the

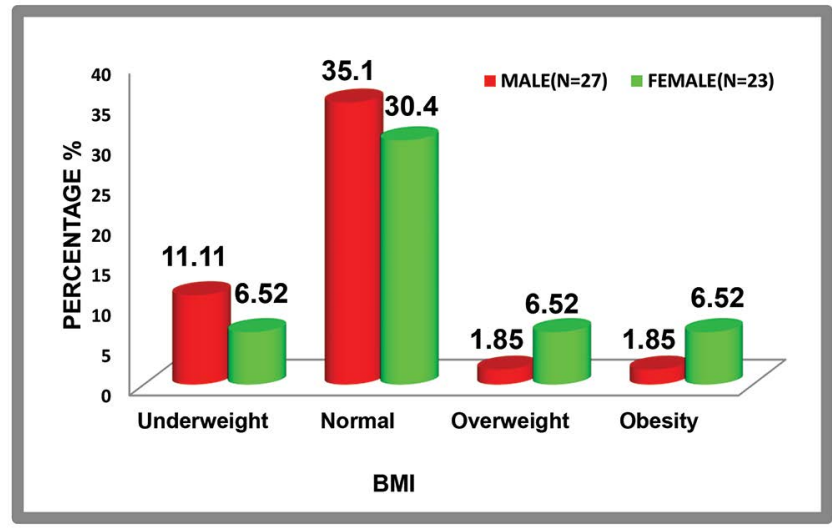

Figure 1. Graphical representation of percentage distribution of subjects based on BMI.

Table 4. Percentage distribution of subjects based on BMI

\begin{tabular}{|c|c|c|c|c|c|}
\hline \multirow{2}{*}{$\begin{array}{c}\text { BMI } \\
\left(\mathbf{k g} / \mathbf{m}^{2}\right)\end{array}$} & \multirow{2}{*}{ Interpretation } & \multicolumn{2}{|c|}{$\begin{array}{c}\text { Male } \\
(\mathrm{N}=\mathbf{2 7})\end{array}$} & \multicolumn{2}{c|}{$\begin{array}{c}\text { Female } \\
(\mathrm{N}=23)\end{array}$} \\
\cline { 3 - 6 } & & $\mathrm{N}$ & $\%$ & $\mathrm{~N}$ & $\%$ \\
\hline$<18.5$ & Underweight & 6 & 11.11 & 3 & 6.52 \\
\hline $18.5-24.9$ & Normal & 19 & 35.1 & 14 & 30.4 \\
\hline $25-29.9$ & Overweight & 1 & 1.85 & 3 & 6.52 \\
\hline$\geq 30$ & Obesity & 1 & 1.85 & 3 & 6.52 \\
\hline
\end{tabular}

study subject's majority of male subjects had $>10 \%$ of weight loss $(24.4 \%)$ and in female subjects $<10 \%$ weight loss was high (17.39 \%) (Table 5).

The mean hemoglobin was found to be less in both male $(11.35 \pm 1.59)$ and female $(10.92 \pm 3.12)$ subjects 
Table 5. Percentage distribution of subjects based on percentage weight loss

\begin{tabular}{|c|c|c|c|c|}
\hline $\begin{array}{c}\text { Percentage Weight } \\
\text { Loss }\end{array}$ & \multicolumn{2}{|c|}{ Male $(\mathrm{N}=27)$} & \multicolumn{2}{c|}{$\begin{array}{c}\text { Female } \\
(\mathrm{N}=23)\end{array}$} \\
\cline { 2 - 5 } & $\mathrm{N}$ & $\%$ & $\mathrm{~N}$ & $\%$ \\
\hline$<10 \%$ & 5 & 9.25 & 8 & 17.39 \\
\hline$>10 \%$ & 13 & 24.0 & 4 & 8.69 \\
\hline$>20$ & 4 & 7.40 & 1 & 2.17 \\
\hline No \% WT Loss & 5 & 9.25 & 10 & 21.73 \\
\hline
\end{tabular}

indicating anemia, whereas the other biochemical parameters such as total protein, serum albumin and globulin were found to be normal in both the male and female subjects.

\subsection{Dietary Pattern}

Diet pattern shows $44.4 \%$ of the male subjects and $39.1 \%$ of female subjects were following mixed diet pattern and only $5.55 \%$ of male subjects and $10.8 \%$ of female subjects were following vegetarian diet. Food frequency study revealed that cereals, milk and milk products were consumed daily by $100 \%$ of the subjects. Other food groups such as pulses, vegetables, green leafy vegetables and fruits seem to be poorly included in the diet.

The male and female subjects had poor intake of energy, protein, carbohydrate and fat compared with recommended daily allowance which could be due to the effect of the underlying disease condition. The nutrient intake of study subjects was poor in energy, protein, carbohydrate and fat compared with recommended daily allowance which could be due to the effect of pain, nausea, vomiting, medication, dry mouth, gastric discomfort and distension, fasting, unpleasant procedures, anxiety, unfamiliar food and hospital routines all factors potentially reduce appetite and intake (Table 6).

Table 6. Mean and standard deviation of 3 days nutrient intake of the study subjects

\begin{tabular}{|c|c|c|}
\hline \multirow{2}{*}{ Nutrients } & $\begin{array}{c}\text { Male } \\
(\mathrm{N}=27) \\
\text { MEAN } \pm \text { SD }\end{array}$ & $\begin{array}{c}\text { Female } \\
(\mathrm{N}=23) \text { MEAN } \\
\pm \text { SD }\end{array}$ \\
\hline \multirow{2}{*}{ Energy (k. cals) } & $360.2 \pm$ & $429.85 \pm$ \\
& 162.8 & 201.61 \\
\hline Protein $(\mathrm{g})$ & $13.59 \pm 5.54$ & $15.97 \pm 6.7$ \\
\hline Carbohydrates $(\mathrm{g})$ & $63.75 \pm$ & $56.53 \pm$ \\
& 37.15 & 28.26 \\
\hline Fat $(\mathrm{g})$ & $8.66 \pm 5.14$ & $7.69 \pm 3.86$ \\
\hline
\end{tabular}

\subsection{GIQLI Assessment}

Female have better Quality of Life scores compared to male subjects except for the emotional domain. All mean scores including overall and domain specific across both the genders were found to be comparatively less than the maximum scores for each category (Table 7).

Table 7. Mean GIQLI scores (overall and domain specific) of the study subjects

\begin{tabular}{|l|c|c|c|}
\hline GIQLI Criteria & $\begin{array}{c}\text { Maximum } \\
\text { Score }\end{array}$ & Male (N=27) & $\begin{array}{c}\text { Female } \\
(\mathrm{N}=23)\end{array}$ \\
\hline Overall (36) & 144 & $77.81 \pm 16.28$ & $\begin{array}{c}79.39 \pm \\
17.08\end{array}$ \\
\hline Physical (8) & 32 & $11.07 \pm 4.17$ & $\begin{array}{c}13.34 \pm \\
3.85\end{array}$ \\
\hline Emotional (9) & 36 & $25 \pm 4.41$ & $\begin{array}{c}12.13 \pm \\
4.19\end{array}$ \\
\hline $\begin{array}{l}\text { Gastrointestinal } \\
(19)\end{array}$ & 76 & $42 \pm 12.04$ & $43 \pm 14.9$ \\
\hline
\end{tabular}

The comparison of GIQLI scores based on domains with upper and lower gastrointestinal diseases does not show any significant difference $(p>0.05 \%)$. When the subject scores were compared with the scores of normal individuals it showed drastic difference indicating that the study subjects had low Quality of Life which could be attributed to the underlying GI disease.

Comparison of GIQLI score with BMI showed there was no significant difference ( $p>0.05$ ) between the GIQLI score (overall and domain specific) and BMI categories but when looking on to the mean GIQLI scores, the obese subjects seemed to have lesser mean score compared to subjects in other BMI categories (Table 8).

The degree and percentage of weight loss between the upper and lower GI diseases showed statistically significant difference at $5 \%$ level $(\mathrm{P}=0.044)$ was observed indicating higher percentage of subjects had weight loss with underlying lower GI diseases.

Physical domain score had positive association with BMI $(\mathrm{P}<0.023)$. Other domains such as (overall, emotional and gastrointestinal) even though had lesser mean score did not show any significant association with BMI ( $>0.05$ ) (Table 9).

On associating the biochemical parameters with GIQLI scores it was found that there was significant 
Table 8. Comparison of GIQLI score (overall and domain specific) with BMI categories

\begin{tabular}{|l|c|c|c|c|c|}
\hline \multirow{2}{*}{$\begin{array}{c}\text { GIQLI Criteria } \\
\begin{array}{c}\text { Overall and Domain } \\
\text { Specific) }\end{array}\end{array}$} & $\begin{array}{c}\text { UW } \\
\text { (Mean } \pm \text { SD) }\end{array}$ & N (Mean \pm SD) & $\begin{array}{c}\text { OW } \\
(\text { Mean } \pm \text { SD) }\end{array}$ & O & \multirow{2}{*}{ P Value } \\
\hline Overall & $84.11 \pm 13.55$ & $78.03 \pm 17.85$ & $86.60 \pm 18.27$ & $75.33 \pm 21.07$ & $0.679^{\mathrm{NS}}$ \\
\hline Physical & $11.89 \pm 3.18$ & $11.33 \pm 3.79$ & $14.80 \pm 5.76$ & $17.00 \pm 4.58$ & $0.130^{\mathrm{NS}}$ \\
\hline Emotional & $24.67 \pm 3.50$ & $25.03 \pm 4.94$ & $25.20 \pm 0.83$ & $26.33 \pm 1.15$ & $0.834^{\mathrm{NS}}$ \\
\hline Gastrointestinal & $47.78 \pm 11.59$ & $41.85 \pm 13.47$ & $43.60 \pm 14.84$ & $31.33 \pm 15.04$ & $0.418^{\mathrm{NS}}$ \\
\hline
\end{tabular}

TUW - Under Weight, N - Normal, OW - Overweight, O - Obese

Table 9. GIQLI scores with anthropometry, biochemical and nutrient intake

\begin{tabular}{|l|c|c|c|c|}
\hline \multirow{2}{*}{\multicolumn{1}{c|}{ BMI }} & \multicolumn{3}{|c|}{ GIQLI Score (Overall and Domain Specific) } \\
\cline { 2 - 5 } & Overall (P value) & Physical (P value) & Emotional (P value) & Gastrointestinal (P value) \\
\hline Biochemical Parameters & $0.891^{\mathrm{NS}}$ & $0.023^{*}$ & $0.432^{\mathrm{NS}}$ & $0.231^{\mathrm{NS}}$ \\
Hemoglobin & & & $\mathrm{C}$ & $\mathrm{D}$ \\
Total count & & & $\mathrm{E}$ & $\mathrm{F}$ \\
Total Protein & $0.226^{\mathrm{NS}}$ & $0.184^{\mathrm{NS}}$ & $0.116^{\mathrm{NS}}$ & $0.416^{\mathrm{NS}}$ \\
Albumin & $0.248^{\mathrm{NS}}$ & $0.384^{\mathrm{NS}}$ & $0.368^{\mathrm{NS}}$ & $0.206^{\mathrm{NS}}$ \\
Globulin & $0.868^{\mathrm{NS}}$ & $0.496^{\mathrm{NS}}$ & $0.875^{\mathrm{NS}}$ & $0.741^{\mathrm{NS}}$ \\
& $0.288^{\mathrm{NS}}$ & $0.131^{\mathrm{NS}}$ & $0.041^{*}$ & $0.674^{\mathrm{NS}}$ \\
\hline Nutrient Intake & $0.314^{\mathrm{NS}}$ & $0.661^{\mathrm{NS}}$ & $0.056^{\mathrm{NS}}$ & $0.522^{\mathrm{NS}}$ \\
Energy & & & $\mathrm{G}$ & $\mathrm{I}$ \\
Protein & & & $\mathrm{H}$ & $\mathrm{J}$ \\
CHO & $0.139^{\mathrm{NS}}$ & $0.100^{\mathrm{NS}}$ & $0.002^{* *}$ & $0.775^{\mathrm{NS}}$ \\
Fat & $0.054^{\mathrm{NS}}$ & $0.087^{\mathrm{NS}}$ & $0.001^{* *}$ & $0.411^{\mathrm{NS}}$ \\
& $0.139^{\mathrm{NS}}$ & $0.99^{\mathrm{NS}}$ & $0.002^{* *}$ & $0.772^{\mathrm{NS}}$ \\
\hline
\end{tabular}

positive association at $5 \%$ level $(\mathrm{P}=0.041)$ with albumin and emotional domain. There was no significant association observed between the overall, physical and GI domain scores with the other biochemical parameters. The findings indicate that Quality of Life does not influenced by the hemoglobin, total count, total protein, albumin and globulin and these factors are predominantly affected by the individual's underlying disease condition and their food intake (Table 9).

When nutrient intake was compared with GIQLI scores (overall and domain specific), the emotional domain showed significant positive association at $1 \%$ level with all the nutrients such as energy $(\mathrm{p}<0.002)$, protein $(\mathrm{p}<0.001)$, carbohydrate $(0.002)$ and fat $(\mathrm{p}<0.001)$ (Table 9).

Having known that nutrition status plays an important role in maintaining the quality of life, in the present study, attempts have been taken in ruling the relationship between nutritional status and Quality of Life using specific GIQLI questionnaire in subjects admitted for GI related surgery.

GIQLI score of the subjects with upper gastro intestinal was found to lesser than the lower GI diseases in accordance with the previous study stating that well-being scores and life scores of an index of daily life were lower among respondents with relevant upper GI symptoms 
than in those who had no upper GI symptoms. The wellbeing and daily life scores were found to discriminate between respondents reporting different symptom frequencies and severity and the results of the Domestic/ International Gastroenterology Surveillance Study (DIGEST) demonstrate on a large scale the importance of GI symptoms in daily life and their influence on HRQL ${ }^{6}$.

Social habits do not have any effect over the Quality of Life but it may be one of the causative factor for occurrence of gastro intestinal complications. Social habits were shown to be associated with impaired levels of health-related Quality of Life and have adverse effect physical and mental wellness. There is no particular effect on gastrointestinal wellness, but social habit involvement leads to negative consequences in later life ${ }^{7}$.

The GIQLI score (overall and domain specific) and BMI categories had no significant difference but when looking on to the mean GIQLI scores, the obese subjects seem to have lesser mean score compared to subjects in other BMI categories. Severe obese patients resulted in a significant impairment of the Quality of Life including social, emotional and physical domain and caused specific gastrointestinal symptoms compared with normal controls.

Physical domain score had positive association with BMI $(\mathrm{P}<0.023)$. Other domains (overall, emotional and gastrointestinal) even though had lesser mean score, it did not show any significant association with BMI. A study done by Kolotkin RL et al., 2001 shows a similar observation that the gastrointestinal Quality of Life is not only being affected by gastrointestinal illness but also due to various other factors in which the Physical Function has the predominant role. Health is affected in terms of psychological, social and physical which has an impact on the nutritional status?.

Nutrient intake of the subjects with varying percentage of weight loss fond to be evident that there is a gradual decline in the nutrient intake as there is increase in the percentage of weight loss. In gastrointestinal disease conditions intake is less leading to fat stores (adipose tissue) and protein stores (lean muscle mass) mobilization to meet the needs of glucose and protein synthesis this in turn results in negative nitrogen balance and weight loss. Patients with gastrointestinal diseases have the catabolic response to increases energy and protein requirements. But various GI complications lead to reduce appetite and intake. Inadequately or unfed patients will rapidly deplete their reserves of protein and fat. This has significant clinical consequences of weight loss, particularly for those with preoperative under nutrition ${ }^{10}$. Gastrointestinal complications mainly affect food intake. A reduction in habitual food intake and weight loss will make patients nutritionally at risk and has a greater frequency of postoperative complications and a longer hospital stay ${ }^{3}$.

\section{Conclusion}

Majority of patients admitted for gastrointestinal surgery have poor quality of life. On assessing the GIQLI in patients admitted for GI surgery the overall and domain specific scores were found to be less when compared with the scores of normal subjects as reported in the previous studies. The overall and domain specific GIQLI scores seem to have association with varying weight loss, serum albumin and nutrient intake. It is well understood that gastrointestinal Quality of Life has major impact on the underlying disease progression and recovery, thus appropriate nutritional intervention and support is recommended to be provided at the earliest to prevent further decline in nutritional status and postoperative complications.

\section{References}

1. McWhirter JP, Pennington CR. The incidence and recognition of malnutrition in hospital. BMJ. 1994; 308:945-8. PMid: 8173401 PMCid: PMC2539799. https://doi.org/10.1136/bmj.308.6934.945

2. Windsor JA, Hill GL. Risk factors for post operative pneumonia: The importance of protein depletion. Ann Surg. 1988; 17:181-5.

3. Carey S. Long-term nutrition intervention following major upper gastrointestinal surgery. Eur J Clin Nut. 2013 Apr; 67(4):324-9. PMid: 23388664. https://doi. org/10.1038/ejen.2013.17

4. De Mendonca Soares BL. Nutritional risk among surgery patients and associations with hospital stay and postoperative complications. Nutr Hosp. 2014 Sep; 30(3):636-41.

5. https://www.who.int/healthinfo/survey/whogol-qualityoflife/en/ 
6. Chen CY. Alcohol use and health-related Quality of Life among youth in Taiwan. J Adolesc Health. 2006 Nov; 39(5):752e9-e16.PMid: 17046514PMCid:PMC2278239. https://doi.org/10.1016/j.jadohealth.2006.04.019

7. Yu PJ, Tsou JJ, Lee WJ, Lee KT. et.al. Impairment of gastrointestinal Quality of Life in severely obese patients. World J Gastroenterol. 2014 Jun; 20(22):702733.

8. Kolotkin RL, Crosby RD, Williams GR. The relationship between health-related Quality of Life and weight loss. Obes Res. 2001 Sep; 9(9):564-71. PMid: 11557837. https://doi.org/10.1038/oby.2001.73

9. Braga M, Gianotti L, Gentilini S, Liotta S, et.al. Feeding the gut early after digestive surgery: Re- sults of a nine-year experience. Clinical Nutrition. 2002 Feb; 21(1):59-65. PMid: 11884014 https://doi. org/10.1054/clnu.2001.0504

10. Daniels L. Good nutrition for good surgery; clinical and Quality of Life outcomes. Aust Prescr. 2003; 6:136-40. https://doi.org/10.18773/austprescr.2003. 100Mae mentique popoeridium atquidio C. Si in tuit, nem taberem etritiu vilingu ltodius, quam optem terorehem iam silis ne inem tanterbit. Am in derestandit.

11. Ideperuris. Si prior pris audem tam publina, me audetid ad consus, quam occhuium prae consciem que 